\section{Medicina Farmacêtica \\ Há vantagens eM SE buscar UM MODELO DE CONTRATO UNIVERSAL PARA ESTUDOS CLÍNICOS PATROCINADOS PELA INDÚSTRIA?}

O contrato jurídico em um estudo clínico é algo que não podeter sua importância subestimada. Assim como ocorre com a avaliação ética, os aspectos legais envolvendo o investigador principal, a instituição onde o estudo acontecerá e os pacientes que dele participarão devem ser definidos antes de o estudo começar, de acordo com ICH-GCP (Internacional Conference on Harmonization - Good Clinical Practices) e ICMJE (International Committee ofMedicalJournal Editors).

Cláusulas que classicamente trazem dúvidas, como o direito de publicação, propriedade intelectual, valores e forma de pagamento, conduta e cobertura em caso de eventos adversos, confidencialidade, acesso aos medicamentos do estudo após a conclusão da pesquisa, procedimento em caso de descontinuação prematura do estudo, etc devem ser contempladas de forma adequada e clara.

O contrato com o patrocinador deve ser assinado, minimamente, pelo pesquisador principal, assim como por um representante legal da instituição. A aprovação do projeto pelo Comitê de Ética em Pesquisa da instituição deve ser adicionada ao processo, antes da assinatura final do contrato, mas não é necessário ter esta aprovação em mãos durante todo o processo de avaliação do contrato. Recomenda-se fortemente, inclusive, que ambos os processos, ético e jurídico, corram em paralelo, evitando-se atraso nas respectivas aprovações' . Algumas instituições possuem um modelo de contrato sugerido, o que deve ser encorajado, uma vez que facilita e acelera a aprovação na instituição ${ }^{1,2}$. Certamente, alguns pontos do contrato poderão gerar discórdia entre a empresa patrocinadora e o centro de pesquisa e algum tempo deve ser previsto para resolver estas questões. A elaboração de um contrato entre as partes deve sempre levar em consideração que as cláusulas devem ser razoáveis para ambos os lados. Esta é a única maneira de se assegurar a precisão e rapidez necessárias ao trâmite do processo.

Iniciativa recentemente empreendida no Reino Unido pela UKCRC (United Kingdom Clinical Research Collaboration)aponta neste sentido, ao definir um modelo de contrato (CTA-Clinical Trial Agreement) que deve ser seguido obrigatoriamente pelas partes envolvidas, a fim de garantir um eficiente processo regulatório e, conseqüentemente, assegurar a participação do país na pesquisa mundial de ponta. Representantes da indústria também participaram do trabalho e acordaram o texto finalmente aprovado. Quatro versões do contrato foram disponibilizadas, refletindo as peculiaridades e legislações de cada região ${ }^{3}$.

Os benefícios deste tipo de iniciativa são evidentes: aperfeiçoa os contratos; referencia legislações locais pertinentes, funcionando como uma fonte educacional; reduz os prazos e custos para aprovação de novos contratos; evita mal-entendidos e discórdias desneces- sárias e, finalmente, atrai os pesquisadores e patrocinadores, dada a facilitação do processo, garantida pela prévia validação ${ }^{4}$.

\section{Sonia Mansoldo Dainesi}

\section{Referências}

I. A Guide to Establishing Clinical Trial Agreements [cited 02 mar 2007]. Avaliable from: http://research.med.wisc.edu/research/research/procedures/ clinical_trial_handbook.html

2. Clinical Trial Site Agreement [cited 03 mar 2007]. Avaliable frim: http:// www.dcri.duke.edu/ccge/contracts/200305 I6_Standard_Site_Agreement.doc. 3. Revised Model Clinical Trial Agreement [cited 03 mar 2007]. http://www.ukcrc.org/ activities/regulationandgovernance/modelclinicaltrialagreement.aspx 4. Goldfarb NM. Standardizing CTAs: International Efforts. A model clinical trial agreement will save both site and sponsor time, money, and resources. Applied Clinical Trials, Feb 2005 [cited 02 mar 2007]. Avaliable from: http://www.actmagazine.com/appliedclinicaltrials/article/ articleDetail.jsp?id = | $4564 \mid$ \&pagelD $=\mid$ \&sk = \&date.

\section{Pediatria \\ MEGACOLO CONGENNTO NO RECÉM-NASCIDO - QUAL $O$ MELHOR TRATAMENTO?}

megacolo congênito, também denominado megacolo aganglionar ou moléstia de Hirschsprung, constitui anomalia congênita grave que, se não diagnosticada e adequadamente tratada, freqüentemente leva o paciente ao óbito. Consiste na ausência de inervação intrínseca na parede intestinal na porção terminal do aparelho digestivo. A forma clássica da doença, que corresponde a 80\% dos casos, decorre da ausência de plexos mioentéricos de Meissner e Auerbach na parede de todo o reto, de forma que o sigmóide torna-se dilatado na tentativa de vencer o obstáculo funcional existente à montante. A doença pode se manifestar no período neonatal, sob forma de suboclusão intestinal baixa e/ou surtos de enterocolite de estase.

Classicamente, até sete anos atrás, o tratamento no recémnascido e lactente jovem era feito por meio de colostomia descompressiva inicial e posterior abaixamento de colo, sendo a técnica de Duhamel a mais utilizada. Desta forma, o tratamento era realizado por meio de cirurgia em dois tempos, com os inconvenientes de uma derivação intestinal temporária.

A partir dos ensinamentos técnicos divulgados pelo cirurgião mexicano Dela Torre-Mondragon, pôde-se padronizar a técnica do abaixamento de colo transretal endoanal em qualquer idade, com anastomose coloanal direta, sem colostomia e sem incisão abdominal. Essa técnica, de inigualável elegância e simplicidade, consiste no descolamento submucoso da parede retal, abordando-se a cavidade peritoneal por dentro do reto.

Pode-se, assim, proceder à de ligadura dos vasos sigmoidianos e ressecar segmentos de colo incluindo a zona aganglionar doente. Finalmente, efetua-se a anastomose do segmento de colo normal 
com o canal anal. O período de íleo paralítico pós-operatório é mínimo, sendo que a maioria das crianças recebe dieta oral no mesmo dia da operação. Tornou-se, assim, indiscutivelmente, a cirurgia de escolha para o recém-nascido com megacolo aganglionar.

A experiência com 40 crianças operadas na Enfermaria do Setor de Cirurgia Pediátrica do Instituto da Criança do Hospital das Clínicas da Faculdade de Medicina da Universidade de São Paulo demonstrou excelentes resultados, com boa continência fecal em $80 \%$ das crianças até dois anos de idade.

Uenis Tannurı
ana Cristina Aoun Tannuri

Referência

De la Torre-Mondragon L, Ortega-Salgado JA. Transanal endorectal pullthrough for Hirschsprung's disease. J Pediatr Surg. 1998;33:1283-6.

Rev Assoc Med Bras 2007; 53(2): 95-107

101 